\title{
REVISED Effect of snail mucus on angiogenesis during wound
}

\section{healing [version 2; peer review: 1 approved, 1 approved with}

\section{reservations]}

\author{
Yosaphat Bayu Rosanto (D1, Cahya Yustisia Hasan (D1), Rahardjo Rahardjo1, \\ Tri Wahyu Pangestiningsih ${ }^{2}$
}

${ }^{1}$ Oral and Maxillofacial Surgery, Faculty of Dentistry, Universitas Gadjah Mada, Yogyakarta, Indonesia, 55281, Indonesia

${ }^{2}$ Anatomy, Faculty of Veterinary Medicine, Universitas Gadjah Mada, Yogyakarta, Indonesia, 55281, Indonesia

V2 First published: 05 Mar 2021, 10:181

https://doi.org/10.12688/f1000research.51297.1

Latest published: 21 May 2021, 10:181

https://doi.org/10.12688/f1000research.51297.2

\section{Abstract}

Background: Angiogenesis is the process through which new blood vessels are formed from existing ones. This process plays an important role in supplying the oxygen and nutrients needed for cellular metabolism and eliminating cell debris during wound healing. Snail mucus can bind to several factors that stimulate angiogenesis, including vascular endothelial growth factor, platelet-derived growth factor, and fibroblast growth factor. The aim of this study is to observe changes in angiogenesis during the healing of wounds topically applied with snail mucus.

Methods: Punch biopsy was performed on the back of male Wistar rats to obtain four wounds, and different concentrations of snail mucus were applied to each of these wounds. The animals were sacrificed on days 2,4 , and 7 to observe the extent of angiogenesis during wound healing by microscopy.

Results: Two-way ANOVA showed differences in number of blood vessels formed $(p=0.00)$ and day of observation $(p=0.00)$ between groups. Post hoc Tukey's HSD test showed that $24 \%$ snail mucus treatment does not significantly affect wound healing $(p=0.488)$; by contrast, treatment with $48 \%$ and $96 \%$ snail mucus demonstrated significant effects on angiogenesis $(p=0.01)$. Spearman's test showed interactive effects between snail mucus concentration and day of observation on the extent of angiogenesis ( $p=0.001, R=0.946)$. Conclusion: Topical application of snail mucus gel can increase angiogenesis during wound healing in Wistar rat skin.

\section{Keywords}

new vessels, hematoxylin eosin, CMC-Na, glycosaminoglycans, heparan sulfate

\section{Open Peer Review \\ Approval Status ? \\ 1 2 \\ version 2 \\ (revision) \\ 21 May 2021 \\ version 1 \\ 05 Mar 2021 \\ view

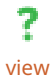 \\ 1. Lidia Audrey Rocha Valadas ID, University of Buenos Aires, Buenos Aires, Argentina \\ Francineudo Oliveira Chagas, Federal \\ University of Ceará, Fortaleza, Brazil \\ 2. Jike Lu iD, Zhengzhou University, \\ Zhengzhou, China \\ Any reports and responses or comments on the article can be found at the end of the article.}


Corresponding author: Cahya Yustisia Hasan (yustisiahasan@ugm.ac.id)

Author roles: Rosanto YB: Conceptualization, Data Curation, Formal Analysis, Funding Acquisition, Investigation, Methodology, Project Administration, Writing - Original Draft Preparation; Hasan CY: Project Administration, Supervision, Validation, Writing - Review \& Editing; Rahardjo R: Supervision, Validation; Pangestiningsih TW: Investigation, Methodology, Supervision

Competing interests: No competing interests were disclosed.

Grant information: The author(s) declared that no grants were involved in supporting this work.

Copyright: ๑ 2021 Rosanto YB et al. This is an open access article distributed under the terms of the Creative Commons Attribution License, which permits unrestricted use, distribution, and reproduction in any medium, provided the original work is properly cited.

How to cite this article: Rosanto YB, Hasan CY, Rahardjo R and Pangestiningsih TW. Effect of snail mucus on angiogenesis during wound healing [version 2; peer review: 1 approved, 1 approved with reservations] F1000Research 2021, 10:181 https://doi.org/10.12688/f1000research.51297.2

First published: 05 Mar 2021, 10:181 https://doi.org/10.12688/f1000research.51297.1 


\section{REVISED Amendments from Version 1}

The mucus was diluted with CMC-Na to obtain gels with mucus concentrations of $24 \%, 48 \%$, and $96 \%(\mathrm{w} / \mathrm{w})$. This concentration produces a gel that is thick enough and does not flow out of the wound. The prepared mucus were stored in polypropylene conical tubes, covered with aluminum foil and placed in the refrigerator at $4^{\circ} \mathrm{C}$. This storage method preserved the angiogenic effect of the mucus. This was evidenced by the number of new blood vessels that were still significantly affected by the results of the study on day 7 . Temperature and light could affect the stability of the mucus so that the used of opaque aluminum foil and cold temperatures could maintain product quality well.

The minimum distance between wounds was $5 \mathrm{~mm}$. The distance between the wounds in this study was made more than $2 \mathrm{~cm}$ so that it does not allow mucus to flow out or affect other groups due to animal movement.

Positive control was not used in this study. The negative control showed a natural angiogenesis process for comparison with the mucus treatment group.

The total rats in each groups are described in Figure 2. (Disclaimer: this image is only an illustration to explain the study grouping, not a photo of each mouse used in this study group).

Any further responses from the reviewers can be found at the end of the article

\section{Introduction}

Oral surgery is an aspect of dentistry that is often associated with skin lesions ${ }^{1,2}$. Cuts to the skin during oral and maxillofacial surgery may be achieved through incision or excision. Incision wounds are usually established during surgery, while excision wounds occur in trauma $\operatorname{cases}^{3-6}$. Excision wound models generally have a diameter of 2-20 mm. Excision wounds provide complex and detailed views of the wound healing process and allow the examination of various wound healing parameters ${ }^{7}$. This fact underlies the selection of excision wound in the present study.

When a wound occurs in the body, physiological healing is performed by multiple biocellular and biochemical processes ${ }^{8}$. Wound healing refers to the process through which normal tissue is regenerated from damaged tissue ${ }^{9}$; it involves cells, the extracellular matrix, and a number of mediators, such as growth factors and cytokines ${ }^{10}$. The wound healing process also involves hemostasis, regeneration of peripheral cells, and restoration of muscle tissue by collagen fibers ${ }^{11}$. Wound healing is a dynamic and complex process that involves multiple phases with overlaps from one phase to another ${ }^{12}$.

The wound healing process can be divided into three phases, namely, inflammation, proliferation, and tissue remodeling. This process can be observed using several parameters, such as re-epithelialization, number of polymorphonuclear leukocytes, number of fibroblasts, density of collagen fibers, and angiogenesis ${ }^{13}$. Angiogenesis is important in healing and refers to the process through which pre-existing blood vessels generate capillary buds to produce new blood vesselss ${ }^{14}$. Angiogenesis is triggered by tissue damage, which causes local hypoxia ${ }^{15}$. When local hypoxia occurs, cells respond by increasing their production of vascular endothelial growth factor (VEGF), one of the most important mediators for wound healing and a stimulant of capillary growth. Angiogenesis is then induced to fulfil requirements for nutrients, oxygen, and inflammatory cells ${ }^{16}$.

Wound healing can be enhanced by chemical and natural treatments ${ }^{17}$. Traditional medicines with natural health benefits and limited side effects have been developed by many researchers ${ }^{18}$. Snail mucus is widely used by cosmetics manufacturers as a skin care material ${ }^{19}$. The resulting products usually feature high contents of hyaluronic acid, proteoglycans, glycoprotein enzymes, and antibacterial peptides to protect the skin from damage $^{20}$.

The African giant snail (Achatina fulica) contains glycosaminoglycans ${ }^{21}$. Indeed, approximately $3 \%-5 \%$ of the dry weight of the snail is composed of glycosaminoglycans ${ }^{22}$. Glycosaminoglycans are a group of anionic polysaccharides that are typically isolated as proteoglycans connected to protein nuclei $^{23}$. The biological activation of glycosaminoglycans stimulates the regulation of cell growth via the interaction of the glycosaminoglycan chains with growth factor proteins and their receptors ${ }^{24}$. The snail also contains acharan sulfate, which is stored as granules in the snail body and secreted by the animal under certain stimuli ${ }^{25}$.

\section{Methods}

Snail mucus gel preparation

The rat cages measured at least $40 \mathrm{~cm}$ long, $15 \mathrm{~cm}$ wide, and $10 \mathrm{~cm}$ high, and one cage housed one rat. The cages were covered with rice husks to achieve a stress-free environment for the rats, and the animals were provided food and water ad libitum. Snails are obtained from farms in Central Java. Identification and determination of Achatina fulica species were carried out in laboratory of animal biology. The snails were adapted to a cage with moist soil and banana leaves as food for three days. Then, the snails were fasted three days before the mucus extraction. Snail mucus was extracted by stimulating the surface of the snail body with an electric shock of $6 \mathrm{~V}$ for $60 \mathrm{~s}$, one touches namely from repetition $2 \sim 4$ times. This method does not cause pain or stress on the snail. A detailed description of all protocols can be found in the google patent numbered CN102846519B (https://patents.google. com/patent/CN102846519B/en). The collected snail mucus was passed through batiste cloth to remove impurities, collected in a glass beaker, and homogenized. The snail mucus was sterilized by filtration through Whatman No. 4 filter paper. Finally, the mucus was diluted with CMC-Na to obtain gels with mucus concentrations of $24 \%, 48 \%$, and $96 \%$ (w/w). This concentration produces a gel that is thick enough and does not flow out of the wound. The prepared mucus were stored in polypropylene conical tubes, covered with aluminum foil and placed in the refrigerator at $4{ }^{\circ} \mathrm{C}$. This storage method preserved the angiogenic effect of the mucus. This was evidenced by the number of new blood vessels that were still significantly affected by the results of the study on day 7 . 
Temperature and light could affect the stability of the mucus so that the used of opaque aluminum foil and cold temperatures could maintain product quality well.

\section{Animals and group preparation}

This research was approved by the Health and Medical Research Ethics Committee of the Faculty of Dentistry, Universitas Gadjah Mada (Approval No. 00272/KKEP/FKG-UGM/ EC/2019). This study used nine rats based on calculations using the resource of equation method with the minimum sample calculation formula in research with ANOVA design. Sample calculation: Minimum $\mathrm{n}=10 / \mathrm{kr}+1=10 /(4 \times 3)+1=1.83$. Maximum $\mathrm{n}=20 / \mathrm{kr}+1=20 /(4 \times 3)+1=2.66(\mathrm{k}=$ number of treatments, $r=$ number of repeated measurements). The conclusion is the use of 3 rats meets the sample size requirements.

The rats were obtained from breeding by laboratory of pharmaceutical. Healthy male Wistar rats were adapted to cages for 3 days. The rat cages measured at least $40 \mathrm{~cm}$ long, $15 \mathrm{~cm}$ wide, and $10 \mathrm{~cm}$ high, and one cage housed one rat. The cages were covered with rice husks to achieve a stress-free environment for the rats, and the animals were provided food and water ad libitum.

\section{Animal treatment}

The rats were included in the study if they were 3-4 months old, weighed 250-300 mg, appeared healthy and physically active, and there were no visible anatomical defects. The rats were excluded in the study if they had postoperative infections or died before the euthanasia process. They were randomly divided into three groups of euthanasia day (three rats/group). Random numbers were generated using the standard $=$ RAND () function in Microsoft Excel. The rats were anesthetized with $100 \mathrm{mg} / \mathrm{kg}$ BW ketamine and $4 \mathrm{mg} / \mathrm{kg}$ xylazine intramuscularly. The back of each rat was shaved, marked, and disinfected with $70 \%$ alcohol. A circular subcutaneous excision wound was made by punch biopsy of $5 \mathrm{~mm}$. The skin on the back of a rat was folded and lifted by pinching the cranial and caudal skin between the thumb and forefinger. The rat was placed in the lateral position, and a biopsy punch was made through the folded skin (middle). Appearance of the resulting symmetrical and full-thickness wounds is shown in Figure 1. The minimum distance between wounds was $5 \mathrm{~mm}$. The distance between the wounds in this study was made more than $2 \mathrm{~cm}$ so that it does not allow mucus to flow out or affect other groups due to animal movement. Each rat was given 4 wounds which were given different experiments $(24 \%, 48 \%, 96 \%$ and control gels), so the total was nine rats with 36 wounds (each experiments were nine wounds which were observed on day two, four, and seven). Positive control was not used in this study. The negative control showed a natural angiogenesis process for comparison with the mucus treatment group. The total rats in each groups are described in Figure 2. (Disclaimer: this image is only an illustration to explain the study grouping, not a photo of each mouse used in this study group). The calculation of the number of samples and four wounds on the back of the rats and this fulfills the requirements of reduce, reuse, and recycle.

The rats were transferred to a warm cage until they regained complete consciousness and then returned to their original cages. The general condition and weight of the rats were recorded daily. The snail mucus $(24 \%, 48 \%, 96 \%)$ and control gels (CMC-Na) were applied $1 \mathrm{ml}$ once a day (in the morning) on each wound. Euthanasia was performed on postoperative days 2, 4, and 7 by overdoses of inhaled anesthetics ether. The skin of the treated wound area was removed for histological examination by hematoxylin-eosin staining. Observation and calculation of the number of new blood vessels formed were carried out using a binocular microscope equipped with an Optilab Advance V2 12,6MP camera in the five fields of view. Microscopic observations were performed at $40 \times, 100 \times$, and $400 \times$ magnification. The number of new blood vessels formed was calculated by three observers. The number of new blood vessels were the only outcome measures used

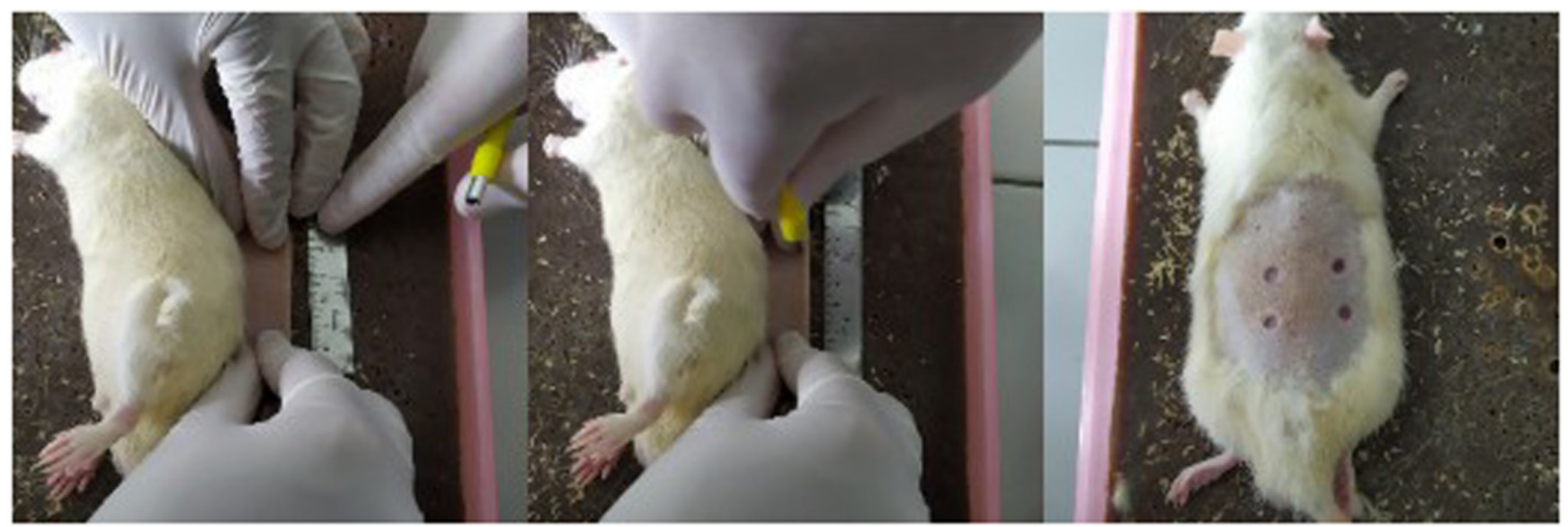

Figure 1. Installation of excision wounds. 


\title{
Day 0: all rats were given wound
}
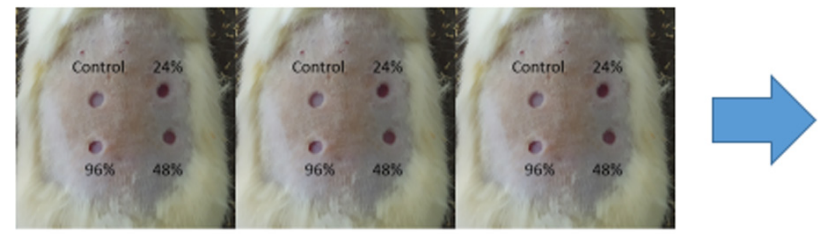

\author{
Group I: Euthanasia \\ was performed on \\ day 2 postoperative
}
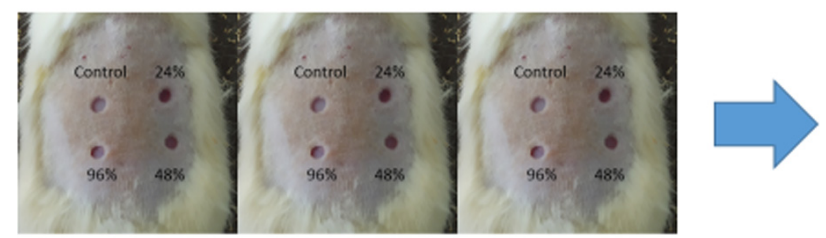

Group II: Euthanasia

was performed on

day 4 postoperative
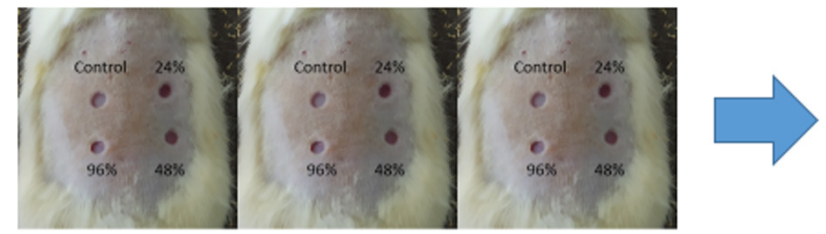

\section{Group III: Euthanasia \\ was performed on \\ day 7 postoperative}

Figure 2. Experimental groups.

\section{Statistical analysis}

Two-way analysis of variance (ANOVA) was used to determine significant differences in angiogenesis among the treatment groups. Post hoc Tukey's test was conducted to determine which groups showed significant differences. Statistical calculations were performed using statistical package for the social sciences (IBM SPSS Statistics 23) software at a confidence level of $95 \%(\alpha<0.05)$

\section{Results}

Observation at $40 \times$ magnification showed differences in the structure of wounds with healthy skin borders on days two, four, and seven at all perecentage of mucus (Figure 3). Wounds observed on day two showed tissues filled with inflammatory cells without a surface epithelium. Wounds on day four revealed reductions in inflammatory tissue and a thin layer of connective tissue. The surface epithelium covering the wound was fairly thin. On day seven of healing, the wounds showed thick connective tissue formation and a surface epithelium layer clearly covering the wounded area. Inflammatory cells could not be clearly observed on day seven.

Observation at $100 \times$ magnification was performed to determine relevant fields of view (Figure 4). Angiogenesis was noted in the papillary and reticular strata. Visual fields for further observation were selected from five areas in these strata.

The number of new blood vessels in the wounds was counted from five fields of view at 400x magnification. New blood vessels appeared in the lumen; the walls of these vessels were composed of endothelial cells and contained erythrocytes
(Figure 5). Endothelial cells at the edges of cell walls were purple in color, round, and flat. Erythrocytes appeared as red irregularly rounded cells without a nucleus.

The number of new blood vessels formed are shown in Figure 6 and Table 1. The results of the calculations in Table 1 are depicted in Figure 7. The number of new blood vessels formed increased from day two to day four in all groups but was greatest in the $96 \%$ snail mucus treatment group (mean, 17.2). Whereas angiogenesis decreased from day four to day seven in the $96 \%$ and $48 \%$ snail mucus treatment groups, angiogenesis in the $24 \%$ snail mucus treatment and control groups increased over these days. The number of new blood vessels formed in the $96 \%$ snail mucus treatment group was consistently greater than those in the other treatment groups on each day assessed.

\section{Data analysis}

Two-way ANOVA was used to determine significant differences in the extent of angiogenesis and number of observation days among the treatment groups. Differences in number of observation days, concentration, and the interaction of number of observation days and concentration were significant with $0.000,0.000$, and $0.001(\mathrm{p}<0.05)$, respectively. These results demonstrate that each of the independent variables analyzed has a significant effect on angiogenesis.

Post hoc testing of the two-way ANOVA results was conducted using Tukey's HSD test. The difference in the number of new blood vessels formed between the control group and the $24 \%$ snail mucus treatment group was not significant. All other groups showed significant differences 


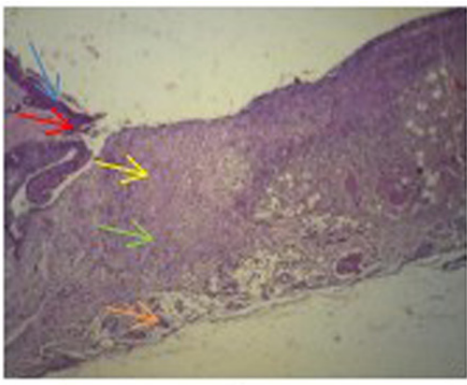

A

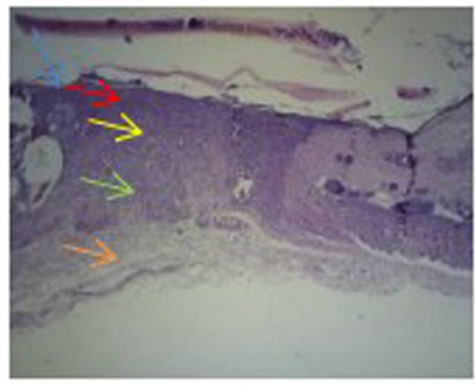

B

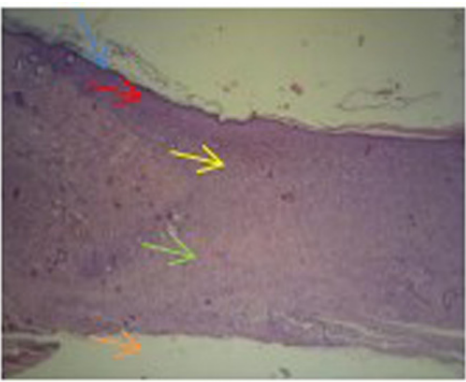

C

Figure 3. Wound healing with gel $96 \%$ on day two $(\mathbf{A})$, day four $(\mathbf{B})$, and day seven $(\mathbf{C})$, as determined using histological preparations with hematoxylin-eosin staining at 40× magnification. Blue arrows indicate the epithelium, red arrows indicate the epidermis, yellow arrows indicate the papillary stratum, green arrows indicate the reticular stratum, and orange arrows indicate adipose layers. Observation of angiogenesis was carried out on the papillary and reticular dermal layers of the stratum.

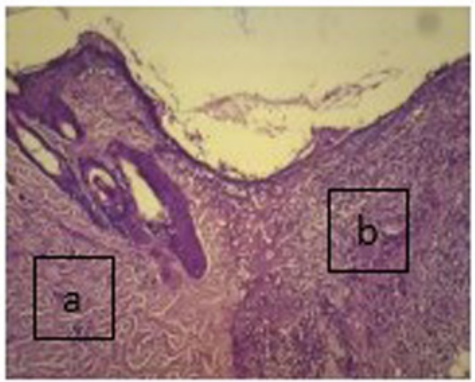

A

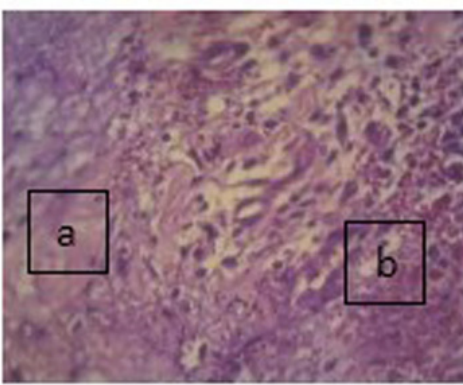

B

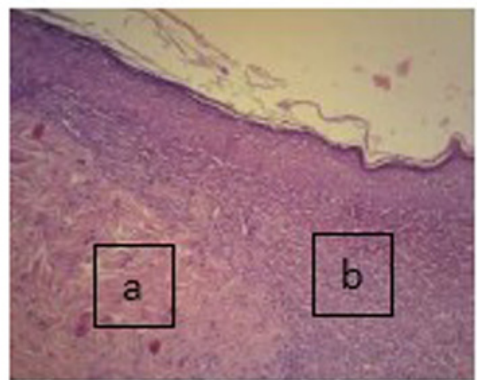

C

Figure 4. Wound healing with gel $96 \%$ on day two (A), day four (B), and day seven (C), as determined using histological preparations with hematoxylin-eosin staining at $100 \times$ magnification. (a) Healthy tissue and (b) wound tissue.

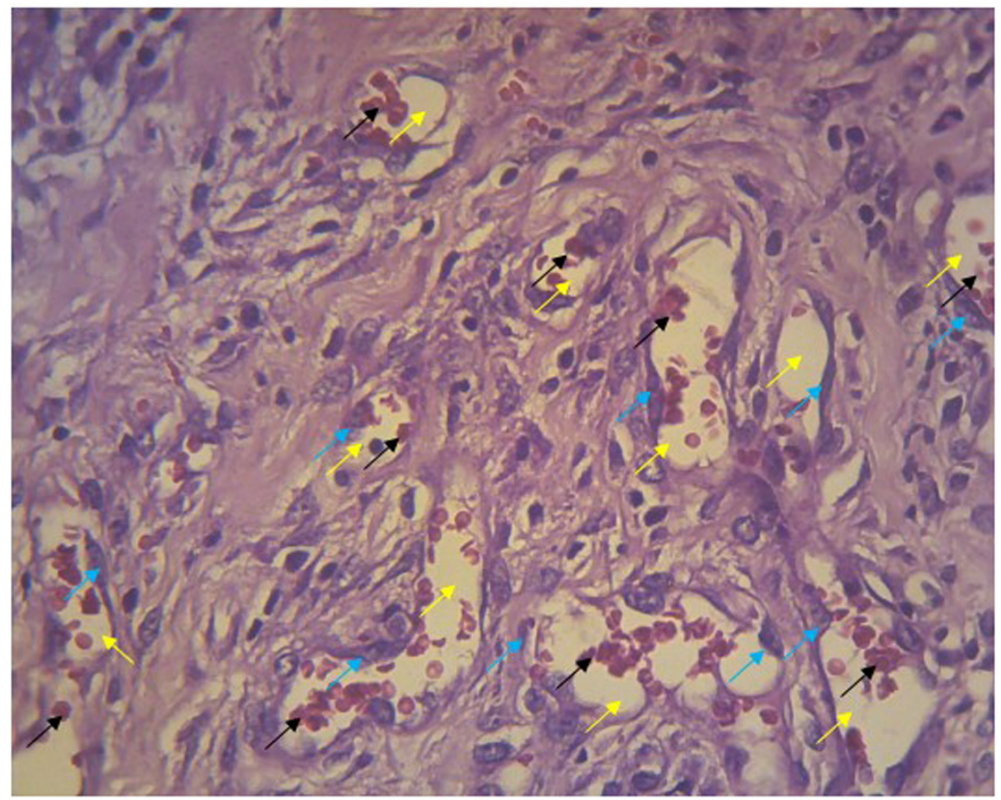

Figure 5. Blood vessels in the histologic preparation. The walls of lumen vessels (yellow arrows) are formed by endothelial cells (blue arrows) and contain erythrocytes (black arrows). This picture was taken from experiments with gel 96\%. 


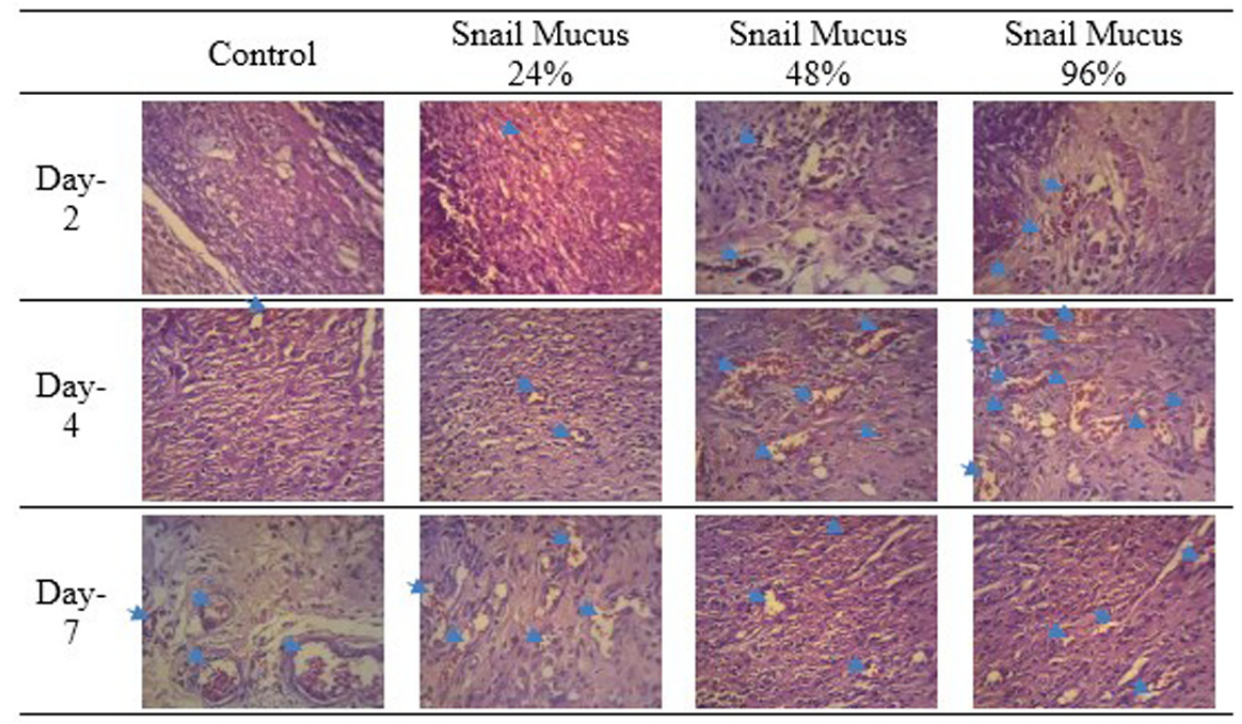

Figure 6. Angiogenesis in the wound area on days two, four, and seven, as observed from histological preparations with hematoxylin-eosin staining at $\mathbf{4 0 0 x}$ magnification. The greatest number of new blood vessels formed was observed on day four following the application of $96 \%$ snail mucus gel $(p=0.000)$.

Table 1. Results of angiogenesis observations according to day and concentration.

\begin{tabular}{|c|c|c|c|c|c|c|c|c|c|c|c|c|c|}
\hline \multirow{3}{*}{ 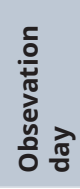 } & \multirow{3}{*}{$\begin{array}{l}\stackrel{4}{0} \\
\frac{n}{0} z \\
\frac{0}{0} \\
\frac{0}{4}\end{array}$} & \multicolumn{12}{|c|}{ Mucus Snail Gel Concentration } \\
\hline & & \multicolumn{3}{|c|}{ Control } & \multicolumn{3}{|c|}{$24 \%$} & \multicolumn{3}{|c|}{$48 \%$} & \multicolumn{3}{|c|}{$96 \%$} \\
\hline & & $\begin{array}{l}\text { Number/ } \\
\text { field }\end{array}$ & Total & Average & $\begin{array}{l}\text { Number/ } \\
\text { field }\end{array}$ & Total & Average & $\begin{array}{l}\text { Number/ } \\
\text { field }\end{array}$ & Total & Average & $\begin{array}{c}\text { Number/ } \\
\text { field }\end{array}$ & Total & Average \\
\hline \multirow{5}{*}{ Day 2} & 1 & 3 & \multirow{5}{*}{13} & \multirow{5}{*}{2.6} & 3 & \multirow{5}{*}{13} & \multirow{5}{*}{2.6} & 4 & \multirow{5}{*}{21} & \multirow{5}{*}{4.2} & 5 & \multirow{5}{*}{29} & \multirow{5}{*}{5.8} \\
\hline & 2 & 2 & & & 3 & & & 5 & & & 6 & & \\
\hline & 3 & 2 & & & 2 & & & 5 & & & 6 & & \\
\hline & 4 & 3 & & & 3 & & & 4 & & & 7 & & \\
\hline & 5 & 3 & & & 2 & & & 3 & & & 5 & & \\
\hline \multirow{5}{*}{ Day 4} & 1 & 10 & \multirow{5}{*}{53} & \multirow{5}{*}{10.6} & 9 & \multirow{5}{*}{59} & \multirow{5}{*}{11.8} & 13 & \multirow{5}{*}{77} & \multirow{5}{*}{15.4} & 16 & & \multirow{5}{*}{17.2} \\
\hline & 2 & 11 & & & 10 & & & 16 & & & 16 & & \\
\hline & 3 & 9 & & & 15 & & & 17 & & & 18 & 86 & \\
\hline & 4 & 13 & & & 13 & & & 14 & & & 19 & & \\
\hline & 5 & 10 & & & 12 & & & 17 & & & 17 & & \\
\hline \multirow{5}{*}{ Day 7} & 1 & 13 & \multirow{5}{*}{58} & \multirow{5}{*}{11.6} & 12 & \multirow{5}{*}{62} & \multirow{5}{*}{12.4} & 12 & \multirow{5}{*}{64} & \multirow{5}{*}{12.8} & 14 & \multirow{5}{*}{67} & \multirow{5}{*}{13.4} \\
\hline & 2 & 10 & & & 13 & & & 12 & & & 13 & & \\
\hline & 3 & 10 & & & 12 & & & 14 & & & 12 & & \\
\hline & 4 & 13 & & & 12 & & & 14 & & & 14 & & \\
\hline & 5 & 12 & & & 13 & & & 12 & & & 14 & & \\
\hline $\begin{array}{r}\text { To } \\
\text { ave }\end{array}$ & & & 41.33 & & & 44.67 & & & 54.00 & & & 60.67 & \\
\hline
\end{tabular}




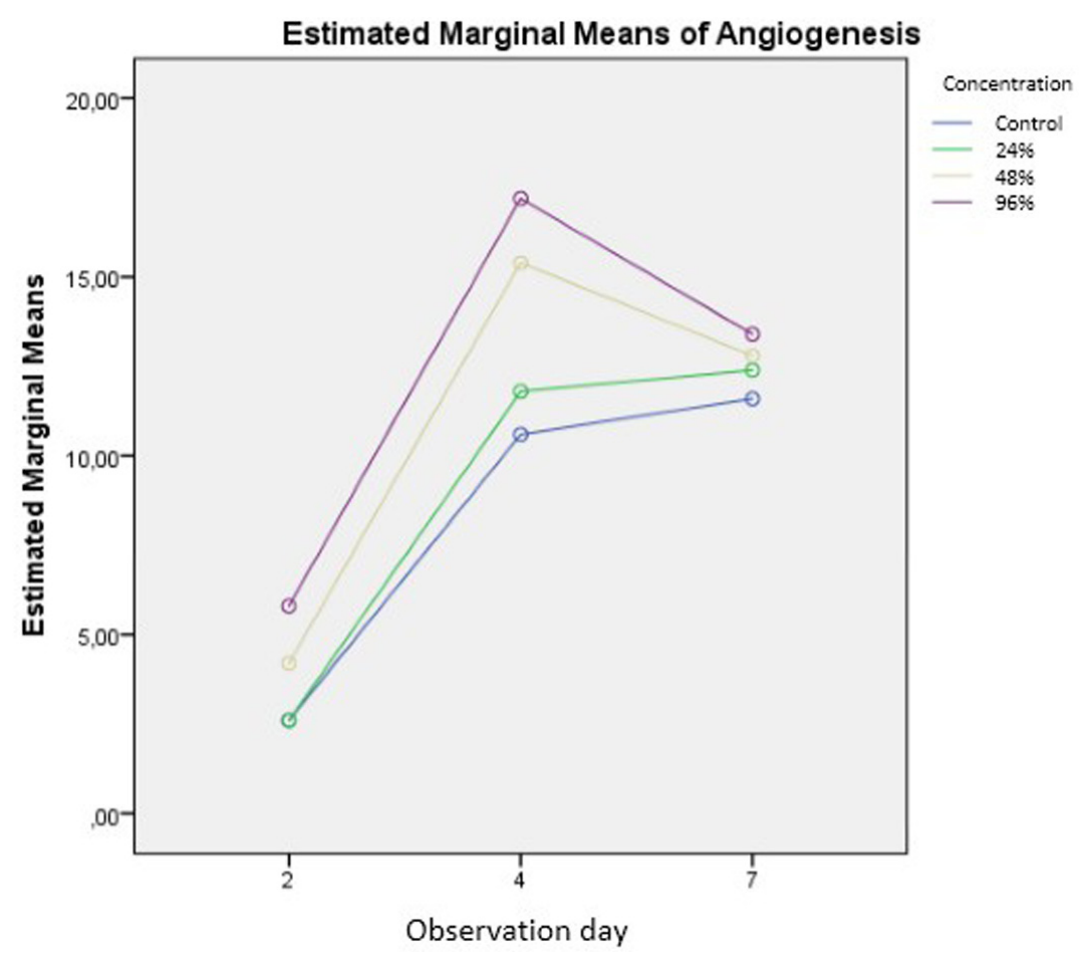

Figure 7. Graphic of the numbers of new blood vessels formed among treatment groups and days.

in mean number of new blood vessels formed. These results indicate that treatment with $48 \%$ and $96 \%$ snail mucus has significant effects on angiogenesis during skin wound healing.

\section{Discussion}

Wound healing is a biological process that involves complex interactions between cells, the extracellular matrix, and growth hormones. This process occurs in several phases, namely, hemostasis, inflammation, proliferation, and maturation ${ }^{26}$. Angiogenesis is an important process in wound healing ${ }^{27}$. The present study demonstrated that snail mucus can accelerate angiogenesis and wound healing. Prasojo et al. (2018) found that pure snail mucus without a carrier material can increase angiogenesis during wound healing compared with distilled water $^{28}$. Harti et al. (2018) showed that heparan sulfate stimulates VEGF. The study found that $5 \%$ and $100 \%$ snail mucus creams could accelerate wound healing by stimulating lymphocyte proliferation $^{29}$.

Xander and Toin $(2013)^{30}$ revealed that heparan sulfate is a proteoglycan that serves as a binder and storage unit for basic fibroblast growth factor (bFGF), which is secreted into the extracellular matrix. Heparan sulfate interacts with proangiogenic factors, such as fibroblast growth factor (FGF), VEGF, and platelet-derived growth factor (PDGF), on the surface of endothelial cells and causes these factors to bind to their corresponding receptors, thereby resulting in dimerization and various signaling processes. The extracellular matrix can release
bFGF to stimulate inflammatory cell recruitment, fibroblast activation, and the formation of new blood vessels during injury $^{31,32}$. This hormonal mechanism may also occur in the increase of angiogenesis in this study. However, research on this subject is still our next research project. In addition, a snail mucus gel formulation is also in our next project, so that this gel will have a more effective absorption rate and can be stored for a long time. A previous study indicated that snail mucus with chitosan as a membrane can accelerate wound healing through anti-inflammatory activity. Apriyanti et al. $(2017)^{33}$ also showed that $5 \%$ snail mucus gel could increase angiogenesis in alveolar bone during the healing of periodontitis in Wistar rats.

Angiogenesis is a complex process involving various cells, hormones, and extracellular components ${ }^{34}$. Snail mucus contains proangiogenic glycosaminoglycans, heparan sulfate, heparin sulfate, and hyaluronic acid. These compounds can increase angiogenesis by triggering VEGF as the dominant angiogenetic growth factor against endothelial cells as blood vessel-forming cells ${ }^{22,35,36}$.

Endothelial cell proliferation marks the beginning of angiogenesis. Endothelial cells grow, migrate, and then attach to the extracellular matrix, where they differentiate into new blood vessels $^{37-39}$. Snail mucus can stimulate these processes remarkably. The results of this study demonstrated that the application of snail mucus could increase angiogenesis at all concentrations tested. The statistical analysis shows that the increase in 
angiogenesis is particularly significant at snail mucus concentrations of $48 \%$ and $96 \%(\mathrm{p}=0.000)$. Compared with the other groups, the $96 \%$ snail mucus treatment showed the greatest extent of angiogenesis (Figure 7).

New blood vessels were formed on day two in all treatments. Wounds applied with snail mucus showed a greater number of new blood vessels formed compared with the control treatment $(\mathrm{p}=0.000)$. This finding is consistent with the research of Bauer et al. (2005) $)^{15}$, who found that the initial factor triggering angiogenesis is the damage that occurs in endothelial tubules following tissue damage. Tissue damage causes local hypoxia. The hypoxic state of the tissue becomes an angiogenic stimulator as growth factors and cytokines are released from inflammatory cells accumulated in the wound area during the previous inflammatory process. These factors stimulate the proliferation and invasiveness of vascular cells to promote blood vessel growth ${ }^{15,16,40}$.

The most important mediators in the early phase of angiogenesis are VEGF, FGF, and $\mathrm{PDGF}^{41}$. Heparan sulfate in snail mucus can interact with these factors on the surface of endothelial cells and enhance their ability to bind to their corresponding receptors, resulting in dimerization and various signaling processes $^{30}$. An adequate supply of nutrients, oxygen, and cells with essential functions in wound healing could hasten the wound healing process. Sufficient nutrition and oxygen are required for optimal wound healing. Angiogenesis provides a new vascular system that could deliver nutrients and oxygen to the wound area and enable wound healing. Cells necessary for wound healing, such as inflammatory cells, fibroblasts, and mesenchymal cells, which secrete various growth factors, may also be delivered to the wound site through this new vascular system $^{42,43}$. Mature endothelial cells can then form new blood vessel walls in the wound area ${ }^{44}$.

Day four of observation revealed the greatest number of new blood vessels formed in the $96 \%$ snail mucus treatment group. The proliferation phase of angiogenesis occurs on the fourth day after the initiation phase, which could explain the extent of angiogenesis observed on this day in the present study. Kalangi $(2004)^{45}$ stated that the proliferation phase begins with the degradation of old blood vessels by providing capillary shoot formation in hypoxic tissues to meet the nutritional and oxygen needs of parenchymal cells. These parenchymal cells secrete the most important proangiogenic growth factor, namely, VEGF-A. Then, there is a series of angiogenesis starting from (1) migration of endothelial cells distally from the original capillary vessels to stimulate angiogenesis; (2) proliferation of endothelial cells at the periphery of/distal to tubule formation; (3) stabilization of endothelial cells by interacting strongly with support cells, such as smooth muscle cells and pericytes; (4) maturation of endothelial cells via the formation of a lumen through intercellular and intracellular mechanisms, including the mobilization and proliferation of pericytes (from blood vessels) and smooth muscle cell (for large vessels) to support the endothelial wall and provide additional budding; (5) anastomosis with other endothelial buds and knot formation; and (6) development of circulation and adjustment of canals with arterial and venous segments ${ }^{45-47}$.

Glycosaminoglycans and heparan sulfate in snail mucus significantly increased $(\mathrm{p}=0.031)$ the number of new blood vessels formed in the $96 \%$ snail mucus treatment group on day four. Glycosaminoglycans stabilize cell membranes, increase the synthesis of hyaluronic acid, a known anti-inflammatory agent, and accelerate angiogenesis; as such, these compounds have positive effects on wound healing ${ }^{48}$. Angiogenesis can also be enhanced by the ability of snail mucus to bind divalent cations, such as copper(II $)^{29}$. Heparan sulfate is a proteogenizer that can bind and store bFGF, which is secreted by the extracellular matrix to stimulate the recruitment of inflammatory cells, fibroblast activation, and angiogenesis ${ }^{49}$.

Compared with that on the day 4 , the average number of new blood vessels formed in the $48 \%$ and $96 \%$ snail mucus treatment groups decreased on day 7. By contrast, the control and $24 \%$ snail mucus treatment groups revealed continuous increases in angiogenesis (Table 1 and Figure 7) significantly ( $p=0.000$ ). This finding indicates that snail mucus not only increases the number of new blood vessels formed but also hastens the phases of angiogenesis. The decrease in number of new blood vessels formed on day seven in the $48 \%$ and $96 \%$ snail mucus treatment groups may be due to apoptosis. The number of new vessels formed is reduced until the density of blood vessels in the wound area returns to normal. This process is regulated by a selective apoptosis process that occurs simultaneously with the maturation of new blood vessels. Apoptosis refers to the automatic and programmed death of normal cells ${ }^{50-52}$.

According to a study conducted by Ricard et al. (2014), the glycosaminoglycans and hyaluronic acid in snail mucus could increase the activity of pericyte cells. Pericyte cells are multifunctional cells capable of maintaining capillary stability and protecting capillaries from negative signals. Some selective apoptosis processes are regulated by pericyte cells ${ }^{51,53}$. Pericytes are only present in newly formed blood vessels. Researchers believe that vessels without pericytes are susceptible to the influence of antiangiogenic agents ${ }^{54}$. The apoptosis of blood vessels in a wound area decreases following the reduction of antiangiogenic factors ${ }^{55}$. Mostafa $(2014)^{56}$ conducted a study on the effect of topical application of synthetic glycosaminoglycans on wound healing in mice and found an increase in wound closure speed; this study used synthetic glycosaminoglycans at a concentration of $2 \%$. The glycosaminoglycans used in the present study are obtained naturally from snail mucus.

The most important mediators in angiogenesis are VEGF, FGF, and PDGF. This study did not examine hormonal levels of these factors to determine the effect of snail mucus on proangiogenic factors. Further research can be conducted to examine the effects of snail mucus on these factors and their corresponding receptors. In addition, a snail mucus gel formulation is also in our next project, so this gel will have a more effective absorption rate and can be stored for a long time. 


\section{Conclusion}

Different concentrations of snail mucus gel revealed different effects on angiogenesis during the healing of punch biopsy wounds on the back skin of Wistar rats. Compared with the control and $24 \%$ and $48 \%$ snail mucus treatment groups, the $96 \%$ snail mucus treatment group showed the greatest improvements in angiogenesis on day $4(\mathrm{p}=0.00)$. Snail mucus concentration and day of observation showed interactive effects on angiogenesis during skin wound healing in Wistar rats $(\mathrm{R}=0.946)$. Specifically, the higher the snail mucus concentration and the greater the number of observation days, the faster the wound healing process.

\section{Data availability}

Underlying data

Figshare: Table 1. Results of angiogenesis observations according to day and concentration ${ }^{56}$. https://doi.org/10.6084/ m9.figshare.13698871.v1

This project contains the following underlying data:

- Table 1. The results of the calculations in Table 1 are depicted in Figure 7. The number of new blood vessels formed increased from day 2 to day 4 in all groups but was greatest in the $96 \%$ snail mucus treatment group (mean, 17.2). Whereas angiogenesis decreased from day 4 to day 7 in the $96 \%$ and $48 \%$ snail mucus treatment groups, angiogenesis in the $24 \%$ snail mucus treatment and control groups increased over these days. The number of new blood vessels formed in the $96 \%$ snail mucus treatment group was consistently greater than those in the other treatment groups on each day assessed.

Figshare: Figure 1. Installation of excision wounds ${ }^{57}$. https://doi. org/10.6084/m9.figshare.14045033.v 1

This project contains the following data:

- JPG file of the installation of excision wounds on the rats. The skin on the back of a rat was folded and lifted by pinching the cranial and caudal skin between the thumb and forefinger. The rat was placed in the lateral position, and a biopsy punch was made through the folded skin (middle). Appearance of the resulting symmetrical and full-thickness wounds. No modifications have been made to this image.

Figshare. Figure 3. Wound healing with gel $98 \%$ on day two (A), day four (B), and day seven (C) ${ }^{58}$. https://doi.org/10.6084/ m9.figshare.14045075.v1

This project contains the following data:

- JPG file showing the wound healing on day 2. Determined using histological preparations with hematoxylineosin staining at $100 \times$ magnification. (a) Healthy tissue and (b) wound tissue. Arrow on the image was made by Microsoft Word 2013. No others modifications have been made to this image.
Figshare. Figure 4. Wound healing with gel $98 \%$ on day two (A), day four (B), and day seven (C) ${ }^{59}$. https://doi.org/10.6084/ m9.figshare. 14045099

This project contains the following data:

- JPG file of wound healing with gel $98 \%$ on day two (A), day four (B), and day seven (C). Determined using histological preparations with hematoxylin-eosin staining at 100× magnification. (a) Healthy tissue and (b) wound tissue. Alphabet on the image was made by Microsoft Word 2013. No others modifications have been made to this image.

Figshare. Figure 5. Blood vessels in the histologic preparation ${ }^{60}$. https://doi.org/10.6084/m9.figshare.14045309

This project contains the following data:

- JPG file of blood vessels in the histologic preparation. The walls of lumen vessels (yellow arrows) are formed by endothelial cells (blue arrows) and contain erythrocytes (black arrows). This picture was taken from experiments with gel 96\%. Arrow on the image was made by Microsoft Word 2013. No others modifications have been made to this image.

Figshare. Figure 6. New blood vessels formation in the wound area on days two, four, and seven $^{61}$. https://doi.org/10.6084/ m9.figshare. 14045342

This project contains the following data:

- JPG file of angiogenesis in the wound area on days two, four, and seven. Observed from histological preparations with hematoxylin-eosin staining at $400 \times$ magnification. The greatest number of new blood vessels formed was observed on day four following the application of $96 \%$ snail mucus gel $(\mathrm{p}=0.000)$. Grouping, naming, and arrow on the image were made by Microsoft Word 2013. No other modifications have been made to this image.

Figshare. Figure 7. Graphic of the numbers of new blood vessels formed among treatment groups and days ${ }^{62}$. https://doi. org/10.6084/m9.figshare.14045351

This project contains the following data:

- JPG graphic of the numbers of new blood vessels formed among treatment groups and days No other modifications have been made to this image.

Figshare. Raw data of new blood vessels observation ${ }^{63}$. https://doi. org/10.6084/m9.figshare.14045369

This project contains the following data:

- .xlxs file of the results of angiogenesis observations according to day and concentration. 
Data are available under the terms of the Creative Commons Zero "No rights reserved" data waiver (CC BY 4.0 Public domain dedication).

\section{Extended data}

Figshare. Figure 3A. Wound healing with gel $96 \%$ on day two $^{64}$. DOI: https://doi.org/10.6084/m9.figshare.14092499

Figshare. Figure 3B. Wound healing with gel $96 \%$ on day four as determined using histological preparations with hematoxylin-eosin staining at 40× magnification ${ }^{65}$. DOI: https:// doi.org/10.6084/m9.figshare. 14092898

Figshare. Figure 3C. Wound healing with gel $96 \%$ on day seven, as determined using histological preparations with hematoxylin-eosin staining at $40 \times$ magnification ${ }^{66}$. DOI: https:// doi.org/10.6084/m9.figshare.14093035

Figshare. Figure 4A. Wound healing with gel $96 \%$ on day two as determined using histological preparations with hematoxylin-eosin staining at $100 \times$ magnification $^{67}$. DOI: https:// doi.org/10.6084/m9.figshare.14093131

Figshare. Figure 4B. Wound healing with gel $96 \%$ on day four as determined using histological preparations with hematoxylin-eosin staining at $100 \times$ magnification ${ }^{68}$. DOI: https:// doi.org/10.6084/m9.figshare. 14093227

Figshare. Figure 4C. Wound healing with gel $96 \%$ on day seven as determined using histological preparations with hematoxylin-eosin staining at 100× magnification ${ }^{69}$. DOI: https:// doi.org/10.6084/m9.figshare.14093289

Figshare. Figure 5. Blood vessels in the histologic preparation. The walls of lumen vessels (yellow arrows) are formed by endothelial cells (blue arrows) and contain erythrocytes (black arrows). This picture was taken from experiments with gel 96\% ${ }^{70}$. DOI: https://doi.org/10.6084/m9.figshare.14093357

Figshare. Figure 6 Day 2 24\%. Angiogenesis in the wound area on day two with control as observed from histological preparations with hematoxylin-eosin staining at $400 \times$ magnification $^{71}$. DOI: https://doi.org/10.6084/m9.figshare.14093419

Figshare. Figure 6 Day $248 \%$. Angiogenesis in the wound area on days two with $48 \%$ of snail mucus as observed from histological preparations with hematoxylin-eosin staining at $400 \times$ magnification $^{72}$. DOI: https://doi.org/10.6084/ m9.figshare. 14093731

Figshare. Figure 6 Day 2 96\%. Angiogenesis in the wound area on days two with $96 \&$ of snail mucus as observed from histological preparations with hematoxylin-eosin staining at $400 \times$ magnification $^{73}$. DOI: https://doi.org/10.6084/ m9.figshare. 14093829

Figshare. Figure 6 Day 2 Control. Angiogenesis in the wound area on days two, four, and seven, as observed from histological preparations with hematoxylin-eosin staining at 400× magnification ${ }^{74}$. DOI: https://doi.org/10.6084/ m9.figshare. 14093891

Figshare. Figure 6 Day 4 24\%. Angiogenesis in the wound area on day four with $24 \%$ of snail mucus as observed from histological preparations with hematoxylin-eosin staining at $400 \times$ magnification $^{75}$. DOI: https://doi.org/10.6084/ m9.figshare. 14093935

Figshare. Figure 6 Day 4 48\%. Angiogenesis in the wound area on day four with $48 \%$ of snail mucus as observed from histological preparations with hematoxylin-eosin staining at $400 \times$ magnification $^{76}$. DOI: https://doi.org/10.6084/ m9.figshare.14094001

Figshare. Figure 6 Day $496 \%$. Angiogenesis in the wound area on day four with $96 \%$ of snail mucus as observed from histological preparations with hematoxylin-eosin staining at $400 \times$ magnification $^{77}$. DOI: https://doi.org/10.6084/ m9.figshare. 14094623

Figshare. Figure 6 Day 4 Control. Angiogenesis in the wound area on day four with control as observed from histological preparations with hematoxylin-eosin staining at $400 \times$ magnification ${ }^{78}$. DOI: https://doi.org/10.6084/ m9.figshare. 14094687

Figshare. Figure 6 Day 7 24\%. Angiogenesis in the wound area on day seven with $24 \%$ of snail mucus as observed from histological preparations with hematoxylin-eosin staining at 400× magnification ${ }^{79}$. DOI: https://doi.org/10.6084/ m9.figshare. 14094751

Figshare. Figure 6 Day $748 \%$. Angiogenesis in the wound area on day seven with $48 \%$ of snail mucus as observed from histological preparations with hematoxylin-eosin staining at 400× magnification ${ }^{80}$. DOI: https://doi.org/10.6084/ m9.figshare. 14094803

Figshare. Figure 6 Day $796 \%$. Angiogenesis in the wound area on day seven with $96 \%$ of snail mucus as observed from histological preparations with hematoxylin-eosin staining at $400 \times$ magnification $^{81}$. DOI: https://doi.org/10.6084/ m9.figshare. 14094849

Figshare. Figure 6 Day 7 Control. Angiogenesis in the wound area on day seven with control as observed from histological preparations with hematoxylin-eosin staining at 400× magnification ${ }^{82}$. DOI: https://doi.org/10.6084/ m9.figshare. 14094919

\section{Acknowledgments}

We thank our colleagues for providing their insights and expertise to this research. 
1. Welsh JD: Medical History of Union Generals. OH: Kent State University Press 2005.

Reference Source

2. Politis C, Schoenaers J, Jacobs R, et al.: Wound healing problems in the mouth. Front Physiol. 2016; 7: 507

PubMed Abstract | Publisher Full Text | Free Full Text

3. Gál P, Toporcer T, Vidinský B, et al.: Simple interrupted percutaneous suture versus intradermal running suture for wound tensile strength measurement in rats: a technical note. Eur Surg Res. 2009; 43(1): 61-5. PubMed Abstract | Publisher Full Text

4. Harlaar JJ, van Ramshorst GH, Nieuwenhuizen J, et al.: Small stitches with small suture distances increase laparotomy closure strength. Am J Surg. 2009; 198(3): 392-5.

PubMed Abstract | Publisher Full Text

5. Lee YS, Yang $\mathrm{HO}$, Shin $\mathrm{KH}$, et al.: Suppression of tumor growth by a new glycosaminoglycan isolated from the African giant snail Achatina fulica. Eur J Pharmacol. 2003; 465(1-2): 191-8.

PubMed Abstract | Publisher Full Text

6. Macpherson N, Lee S: Effect of different suture techniques on tension dispersion in cutaneous wounds: a pilot study. Australas J Dermatol. 2010; 51(4): 263-7.

PubMed Abstract | Publisher Full Text

7. Azevedo LH, de Sousa SC, Correa L, et al.: Mast cell concentration in the wound healing process of incisions made by different instruments. Lasers Med Sci. 2009; 24(4): 585-90.

PubMed Abstract | Publisher Full Text

8. de Oliveira Gonzalez AC, Costa TF, de Araújo Andrade Z, et al.: Wound healing - A literature review. An Bras Dermatol. 2016; 91(5): 614-20. PubMed Abstract | Publisher Full Text | Free Full Text

9. Krafts KP: Tissue repair: The hidden drama. Organogenesis. 2010; 6(4): 225-33.

PubMed Abstract | Publisher Full Text | Free Full Text

10. Velnar T, Bailey T, Smrkolj V: The wound healing process: an overview of the cellular and molecular mechanisms. J Int Med Res. 2009; 37(5): 1528-42. PubMed Abstract | Publisher Full Text

11. Cañedo-Dorantes L, Cañedo-Ayala M: Skin acute wound healing: $A$ comprehensive review. Int J Inflam. 2019; 2019: 3706315. PubMed Abstract | Publisher Full Text | Free Full Text

12. Guo S, Dipietro LA: Factors affecting wound healing. J Dent Res. 2010; 89(3): 219-29.

PubMed Abstract | Publisher Full Text | Free Full Text

13. van der Laan AM, Piek JJ, van Royen N: Targeting angiogenesis to restore the microcirculation after reperfused MI. Nat Rev Cardiol. 2009; 6(8): 515-23. PubMed Abstract | Publisher Full Text

14. Kumar V, Abbas AK, Fausto N, et al.: Robbins Basic Pathology. London: Elsevier. 2007.

Reference Source

15. Bauer SM, Bauer RJ, Velazques OC: Angiogenesis, vasculogenesis, and induction of healing in chronic wounds. Vasc Endovascular Surg. 2005; 39(4): 293-305.

PubMed Abstract | Publisher Full Text

16. Szpaderska AM, Walsh CG, Steinberg MJ, et al.: Distinct patterns of angiogenesis in oral and skin wounds. J Dent Res. 2005; 84(4): 309-14. PubMed Abstract | Publisher Full Text

17. Sivamani RK, Ma BR, Wehrli LN, et al: Phytochemicals and naturally derived substances for wound healing. Adv Wound Care (New Rochelle). 2012; 1(5): 213-7.

PubMed Abstract | Publisher Full Text | Free Full Text

18. Yuan $\mathrm{H}, \mathrm{Ma} \mathrm{Q}$, Ye $\mathrm{L}$, et al:: The traditional medicine and modern medicine from natural products. Molecules. 2016; 21(5): 559. PubMed Abstract | Publisher Full Text | Free Full Text

19. Dermatol Rev. Snail cream. 2018.

20. Cilia G, Fratini F: Antimicrobial properties of terrestrial snail and slug mucus. J Complement Integr Med. 2018; 15(3). PubMed Abstract | Publisher Full Text

21. Shim JY, Lee YS, Jung SH, et al.: Pharmacological activities of a new glycosaminoglycan, acharan sulfate isolated from the giant African snail Achatina fulica. Arch Pharm Res. 2002; 25(6): 889-94. PubMed Abstract | Publisher Full Text

22. Jeong J, Toida T, Muneta Y, et al.: Localization and characterization of acharan sulfate in the body of the giant African snail Achatina fulica. Comp Biochem Physiol B Biochem Mol Biol. 2001; 130(4): 513-9. PubMed Abstract | Publisher Full Text

23. Pomin VH, Mulloy B: Glycosaminoglycans and proteoglycans. Pharmaceuticals (Basel). 2018; 11(1): 27

PubMed Abstract | Publisher Full Text | Free Full Text

24. Kim HS, Lee $Y H$, Lee YR, et al.: Activation of professional antigen presenting cells by Acharan sulfate isolated from giant African snail, achatina fulica.
Arch Pharm Res. 2007; 30(7): 866-70.

PubMed Abstract | Publisher Full Text

25. Kim HJ, Ulagessan S: Antibacterial and antifungal activities of proteins extracted from seven different snails. App/ Sci. 2018; 8(8): 1362 Publisher Full Text

26. Gurtner GC, Werner $S$, Barrandon $Y$, et al.: Wound repair and regeneration. Nature 2008; 453(7193): 314-21. PubMed Abstract | Publisher Full Text

27. Zeng Z, Zhu BH: Arnebin-1 promotes the angiogenesis of human umbilical vein endothelial cells and accelerates the wound healing process in diabetic rats. J Ethnopharmacol. 2014; 154(3): 653-62. PubMed Abstract | Publisher Full Text

28. Prasojo S, Rahajoe PS, Hasan CY: Effect of Snail Mucus (Achatina fulica) on Increased Angiogenesis in Skin Incision Wounds of Mice (Mus musculus) (Immunohistochemical Study CD34). Thesis. Universitas Gadjah Mada. 2018.

29. Harti AS, Murharyati A, Sulisetyawati DS, et al.: The effectiveness of snail mucus (Achatina fulica) and chitosan toward limfosit proliferation in vitro. Asian J Pharm Clin Res. 2018; 11(15): 85-88.

Publisher Full Text

30. van Wijk XMR, van Kuppevelt TH: Heparan sulfate in angiogenesis: a target for therapy. Angiogenesis. Springer 2014; 17(3): 443-62. PubMed Abstract | Publisher Full Text

31. Ucuzian AA, Gassman AA, East AT, et al:: Molecular mediators of angiogenesis. J Burn Care Res. 2010; 31(1): 158-75.

PubMed Abstract | Publisher Full Text | Free Full Text

32. Fuster MM, Wang L: Endothelial heparan sulfate in angiogenesis. Prog $\mathrm{Mol}$ Biol Trans/ Sci. 2010; 93: 179-212. PubMed Abstract | Publisher Full Text | Free Full Text

33. Apriyanti T, Herawati D, Lastiany SP: Effect of $\mathbf{5 \%}$ Snail Mucus Gel (Achatina fulica) Application on Alveolar Bone Angiogenesis in Periodontitis Healing Process (Study on Wistar). Yogyakarta: UGM ETD. 2017. Reference Source

34. Lamalice L, Le Boeuf F, Huot J: Endothelial cell migration during angiogenesis. Circ Res. 2007; 100(6): 782-94. PubMed Abstract | Publisher Full Text

35. Vieira TCRG, Costa-Filho A, Salgado NC, et al:: Acharan sulfate, the new glycosaminoglycan from Achatina fulica Bowdich 1822. Structural heterogeneity, metabolic labeling and localization in the body, mucus and the organic shell matrix. EurJ Biochem. 2004; 271(4): 845-54. PubMed Abstract | Publisher Full Text

36. Dominic J: Formulation and evaluation of giant African snail (achatina fulica) mucus and chitosan composite films for cicatrization. University of San Agustin. Filipina. College of Pharmacy and Medical Technology. 2015.

37. Ingber DE: Mechanical signaling and the cellular response to extracellular matrix in angiogenesis and cardiovascular physiology. Circ Res. 2002; 91(10): 877-87.

PubMed Abstract | Publisher Full Text

38. Norton KA, Popel AS: Effects of endothelial cell proliferation and migration rates in a computational model of sprouting angiogenesis. Sci Rep. 2016; 6 : 36992.

PubMed Abstract | Publisher Full Text | Free Full Text

39. Mardiyantoro F, Prasetyaningrum N, Rahmastuti HT: Histopathological characteristics of dental socket healing on collagen density following use of pangas catfish (Pangasius djambal) gelatin. Majalah Kedokteran Gigi Indonesia. 2019; 5(3): 120-5.

Publisher Full Text

40. Fermillian A, Agustina D, Subagyo G: The effect of papaya leaf extract (Carica papaya L.) on healing process of buccal traumatic ulcer in Wistar rats. MKGI. 2019; 5(1): 15-22.

Publisher Full Text

41. Adair TH, Montani JP: Angiogenesis. San Rafael: Morgan \& Claypool Life Sciences. 2010.

PubMed Abstract

42. Khakoo AY, Finkel T: Endothelial progenitor cells. Annu Rev Med. 2005; 56: 79-101.

PubMed Abstract | Publisher Full Text

43. Milkiewicz M, Ispanovic E, Doyle JL, et al.: Regulators of angiogenesis and strategies for their therapeutic manipulation. Int J Biochem Cell Biol. 2006; 38(3): 333-57.

PubMed Abstract | Publisher Full Text

44. Fidler IJ, Ellis LM: Neoplastic angiogenesis--not all blood vessels are created equal. N EnglJ Med. 2004; 351(3): 215-6. PubMed Abstract | Publisher Full Text

45. Kalangi SJR: The role of collagen in wound healing. Dexa Media. 2004; 17(4): $168-74$.

46. Jimmy S, Elmarakby D, Gazia MA, et al.: The role of hepatic stellate cells and angiogenesis in liver regeneration following partial hepatectomy in adult male albino rats: histological and immunohistochemical study. Egyptian 
Journal of Histology. 2019; 42(4): 1070-1095. Publisher Full Text

47. Eldien HMS, Mostafa NA, ElTawab OA, et al.: Effect of hematopoietic stem cells and platelet-rich plasma on the healing of experimental skin burned tissues: A comparative study in adult male mice. Egyptian Journal of Histology. 2019; 42(3): 740-754. Publisher Full Text

48. Towheed TE, Maxwell L, Anastassiades TP, et al.: Glucosamine therapy for treating osteoarthritis. Cochrane Database Syst Rev. 2005; 18(2): CD002946. PubMed Abstract | Publisher Full Text

49. Ricard N, Tu L, Le Hiress M, et al.: Increased pericyte coverage mediated by endothelial-derived fibroblast growth Factor-2 and interleukin- 6 is a source of smooth muscle-like cells in pulmonary hypertension. Circulation. 2014; 129(15): 1586-97.

PubMed Abstract | Publisher Full Text

50. Honnegowda TM, Kumar P, Udupa EGP, et al.: Role of angiogenesis and angiogenic factors in acute and chronic wound healing. Plast Aesthet Res. 2015; 2: 243-9. Publisher Full Text

51. DiPietro LA: Angiogenesis and wound repair: when enough is enough. J Leukoc Biol. 2016; 100(5): 979-984.

PubMed Abstract | Publisher Full Text | Free Full Text

52. Attia G, Atef H, Elmansy R: Autologous platelet rich plasma enhances satellite cells expression of MyoD and exerts angiogenic and antifibrotic effects in experimental rat model of traumatic skeletal muscle injury. Egyptian Journal of Histology. 2017; 40(4): 443-458. Publisher Full Text

53. Kelly-Goss MR, Sweat RS, Stapor PC, et al.: Targeting pericytes for angiogenic therapies. Microcirculation. 2014; 21(4): 345-57.

PubMed Abstract | Publisher Full Text | Free Full Text

54. Dulmovits BM, Herman IM: Microvascular remodeling and wound healing: a role for pericytes. Int J Biochem Cell Biol. 2012; 44(11): 1800-12. PubMed Abstract | Publisher Full Text | Free Full Text

55. Wietecha MS, Król MJ, Michalczyk ER, et al.: Pigment epithelium-derived factor as a multifunctional regulator of wound healing. Am J Physiol Heart Circ Physiol. 2015; 309(5): H812-26.

PubMed Abstract | Publisher Full Text | Free Full Text

56. Rosanto YB: Table 1. Results of angiogenesis observations according to day and concentration. figshare. Dataset. 2021. http://www.doi.org/10.6084/m9.figshare.13698871.v1

57. Rosanto YB: Installation of excision wounds. figshare. Figure. 2021. http://www.doi.org/10.6084/m9.figshare.14045033.v1

58. Rosanto YB: Wound healing on day two. figshare. Figure. 2021. http://www.doi.org/10.6084/m9.figshare.14045075.v1

59. Rosanto YB: Wound healing with gel $98 \%$ on day two (A), day four (B), and day seven (C). figshare. Figure. 2021 http://www.doi.org/10.6084/m9.figshare.14045099.v1

60. Rosanto YB: Blood vessels in the histologic preparation. figshare. Figure.
2021.

http://www.doi.org/10.6084/m9.figshare.14045309.v1

61. Rosanto YB: Angiogenesis in the wound area on days two, four, and seven. figshare. Figure. 2021.

http://www.doi.org/10.6084/m9.figshare.14045342.v1

62. Rosanto YB: Graphic of the numbers of new blood vessels formed among treatment groups and days. figshare. Figure. 2021. http://www.doi.org/10.6084/m9.figshare.14045351.v1

63. Rosanto YB: Raw data. figshare. Dataset. 2021. http://www.doi.org/10.6084/m9.figshare.14045369.v1

64. Rosanto YB: Figure 3A. figshare. Figure. 2021. http://www.doi.org/10.6084/m9.figshare.14092499.v1

65. Rosanto YB: Figure 3B. figshare. Figure. 2021. http://www.doi.org/10.6084/m9.figshare.14092898.v1

66. Rosanto YB: Figure 3C. figshare. Figure. 2021. http://www.doi.org/10.6084/m9.figshare.14093035.v1

67. Rosanto YB: Figure 4A. figshare. Figure. 2021. http://www.doi.org/10.6084/m9.figshare.14093131.v1

68. Rosanto YB: Figure 4B. figshare. Figure. 2021. http://www.doi.org/10.6084/m9.figshare.14093227.v1

69. Rosanto YB: Figure 4C. figshare. Figure. 2021. http://www.doi.org/10.6084/m9.figshare.14093289.v1

70. Rosanto YB: Figure 4. figshare. Figure. 2021. http://www.doi.org/10.6084/m9.figshare.14093357.v1

71. Rosanto YB: Figure 6 Day 2 24\%. figshare. Figure. 2021. http://www.doi.org/10.6084/m9.figshare.14093419.v1

72. Rosanto YB: Figure 6 Day $\mathbf{2}$ 48\%. figshare. Figure. 2021. http://www.doi.org/10.6084/m9.figshare.14093731.v1

73. Rosanto YB: Figure 6 Day $\mathbf{2}$ 96\%. figshare. Figure. 2021. http://www.doi.org/10.6084/m9.figshare.14093829.v1

74. Rosanto YB: Figure 6 Day 2 Control. figshare. Figure. 2021. http://www.doi.org/10.6084/m9.figshare.14093891.v1

75. Rosanto YB: Figure 6 Day $\mathbf{4}$ 24\%. figshare. Figure. 2021. http://www.doi.org/10.6084/m9.figshare.14093935.v1

76. Rosanto YB: Figure 6 Day 4 48\%. figshare. Figure. 2021. http://www.doi.org/10.6084/m9.figshare.14094001.v1

77. Rosanto YB: Figure 6 Day 4 96\%. figshare. Figure. 2021. http://www.doi.org/10.6084/m9.figshare.14094623.v1

78. Rosanto YB: Figure 6 Day 4 Control. figshare. Figure. 2021. http://www.doi.org/10.6084/m9.figshare.14094687.v1

79. Rosanto YB: Figure 6 Day 7 24\%. figshare. Figure. 2021. http://www.doi.org/10.6084/m9.figshare.14094751.v1

80. Rosanto YB: Figure 6 Day 7 48\%. figshare. Figure. 2021. http://www.doi.org/10.6084/m9.figshare.14094803.v1

81. Rosanto YB: Figure 6 Day 7 96\%. figshare. Figure. 2021. http://www.doi.org/10.6084/m9.figshare.14094849.v1

82. Rosanto YB: Figure 6 Day 7 Control. figshare. Figure. 2021. http://www.doi.org/10.6084/m9.figshare.14094919.v1 


\section{Open Peer Review}

\section{Current Peer Review Status:}

\section{Version 2}

Reviewer Report 17 May 2022

https://doi.org/10.5256/f1000research.56728.r85908

(C) 2022 Valadas $L$ et al. This is an open access peer review report distributed under the terms of the Creative Commons Attribution License, which permits unrestricted use, distribution, and reproduction in any medium, provided the original work is properly cited.

\section{Lidia Audrey Rocha Valadas}

University of Buenos Aires, Buenos Aires, Argentina

Francineudo Oliveira Chagas

Federal University of Ceará, Fortaleza, Brazil

The suggestions were followed. I suggest acceptance for indexing.

Competing Interests: No competing interests were disclosed.

Reviewer Expertise: pharmacology

We confirm that we have read this submission and believe that we have an appropriate level of expertise to confirm that it is of an acceptable scientific standard.

\section{Version 1}

Reviewer Report 04 May 2021

https://doi.org/10.5256/f1000research.54450.r82617

(C) $2021 \mathrm{Lu} \mathrm{J}$. This is an open access peer review report distributed under the terms of the Creative Commons Attribution License, which permits unrestricted use, distribution, and reproduction in any medium, provided the original work is properly cited.

Jike Lu

School of Life Sciences, Zhengzhou University, Zhengzhou, Henan, China

This is an interesting study on the angiogenesis of crude snail mucus without purification. 
About the "Snail mucus gel preparation", how to store the prepared mucus, or how to ensure the stability of snail mucus during the animal experiments in seven days?

About the animal experiments, a positive control group is recommended. How to ensure that the mucus ( $1 \mathrm{~mL}$ applied on each wound) does not flow out or affect other groups due to animal movement? Description about the animal cage and environment is repeated.

Figure 2, Group 1-3 shows similar photos. It is suggested to list the wound photos at different days to observe the wound healing.

The work is descriptive and needs more mechanisms of research.

\section{References}

1. Song Y, Cui Y, Hao L, Zhu J, et al.: Wound-healing activity of glycoproteins from white jade snail (Achatina fulica) on experimentally burned mice.Int J Biol Macromol. 2021; 175: 313-321 PubMed

Abstract | Publisher Full Text

Is the work clearly and accurately presented and does it cite the current literature? Partly

Is the study design appropriate and is the work technically sound?

Partly

Are sufficient details of methods and analysis provided to allow replication by others? Yes

If applicable, is the statistical analysis and its interpretation appropriate? Yes

Are all the source data underlying the results available to ensure full reproducibility? Yes

Are the conclusions drawn adequately supported by the results?

Yes

Competing Interests: No competing interests were disclosed.

Reviewer Expertise: Natural product chemistry.

I confirm that I have read this submission and believe that I have an appropriate level of expertise to confirm that it is of an acceptable scientific standard, however I have significant reservations, as outlined above. 
Yosaphat Bayu Rosanto, Universitas Gadjah Mada, Yogyakarta, Indonesia

The mucus was diluted with CMC-Na to obtain gels with mucus concentrations of $24 \%, 48 \%$, and $96 \%(\mathrm{w} / \mathrm{w})$. This concentration produces a gel that is thick enough and does not flow out of the wound. The prepared mucus were stored in polypropylene conical tubes, covered with aluminum foil and placed in the refrigerator at $4{ }^{\circ} \mathrm{C}$. This storage method preserved the angiogenic effect of the mucus. This was evidenced by the number of new blood vessels that were still significantly affected by the results of the study on day 7. Temperature and light could affect the stability of the mucus so that the used of opaque aluminum foil and cold temperatures could maintain product quality well.

The minimum distance between wounds was $5 \mathrm{~mm}$. The distance between the wounds in this study was made more than $2 \mathrm{~cm}$ so that it does not allow mucus to flow out or affect other groups due to animal movement.

Positive control was not used in this study. The negative control showed a natural angiogenesis process for comparison with the mucus treatment group.

The total rats in each groups are described in Figure 2. (Disclaimer: this image is only an illustration to explain the study grouping, not a photo of each mouse used in this study group).

Competing Interests: No competing interests were disclosed.

Reviewer Report 22 March 2021

https://doi.org/10.5256/f1000research.54450.r81121

(C) 2021 Valadas L. This is an open access peer review report distributed under the terms of the Creative Commons Attribution License, which permits unrestricted use, distribution, and reproduction in any medium, provided the original work is properly cited.

\section{Lidia Audrey Rocha Valadas}

University of Buenos Aires, Buenos Aires, Argentina

In general the work is interesting and well designed and with appropriate methodology and details that guarantee reproducibility.

The introduction is clear but i suggest to add the importance of the new patent on the field.

I suggest to make the conclusion more concise, without statistical data, on this topic you just need to answer the objective of the study. 
Is the work clearly and accurately presented and does it cite the current literature?

Yes

Is the study design appropriate and is the work technically sound?

Yes

Are sufficient details of methods and analysis provided to allow replication by others?

Yes

If applicable, is the statistical analysis and its interpretation appropriate?

Yes

Are all the source data underlying the results available to ensure full reproducibility?

Yes

Are the conclusions drawn adequately supported by the results?

Yes

Competing Interests: No competing interests were disclosed.

Reviewer Expertise: pharmacology

I confirm that I have read this submission and believe that I have an appropriate level of expertise to confirm that it is of an acceptable scientific standard.

The benefits of publishing with F1000Research:

- Your article is published within days, with no editorial bias

- You can publish traditional articles, null/negative results, case reports, data notes and more

- The peer review process is transparent and collaborative

- Your article is indexed in PubMed after passing peer review

- Dedicated customer support at every stage

For pre-submission enquiries, contact research@f1000.com 